\section{Analysis of first permanent molar condition on Kindergarten student aged 5-6 years old in Eastern Suburban Area of Makassar City}

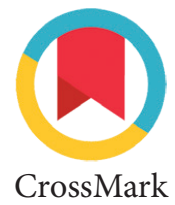

\author{
Marhamah, ${ }^{1}$ Rafikah Hasyim, ${ }^{2 *}$ Dwi P. Wulansari, ${ }^{3}$ Muliaty Yunus, ${ }^{3}$ \\ Hendrastuty Handayani, ${ }^{1}$ Sumintarti, ${ }^{4}$ Sri Ramadhany ${ }^{5}$
}

\title{
Abstract
}

Objective: The aim of this study was to analyze the first permanent molar condition on kindergarten student aged 5-6 years old in eastern suburban area of Makassar city.

Material and methods: This study was a descriptive observational study on 100 kindergarten students from four schools in Tamalanrea District, Makassar City. Data was collected with clinical examination and interview. Data was gathered in terms of DMFT status of first permanent molar and OHI-S. Data was analyzed with descriptive statistics and t-test. In this descriptive cross-sectional study. Statistical analysis was performed by descriptive statistics and t-test.

Results: Mean DMFT of first permanent molars was $1.00 \pm 1.10$, with a higher value seen among boys. Mean decayed teeth component was 0.95 , followed by filled $(0.10)$ and missing $(0.0)$ components.

Conclusion: The observed oral hygiene status among the 5-6 yearolds necessitates implementing pre-ventive as well as restorative measures to improve the oral health status of the young population.
'Department of Pediatric Dentistry, Faculty of Dentistry, Hasanuddin University, Makassar ${ }^{2}$ Department of Oral Biology, Faculty of Dentistry, Hasanuddin University, Makassar

${ }^{3}$ Department of Dental Radiology, Faculty of Dentistry, Hasanuddin University, Makassar ${ }^{4}$ Department of Oral Medicine Department, Faculty of Dentistry, Hasanuddin University, Makassar ${ }^{5}$ Department of Public Health Department, Faculty of Medicine, Hasanuddin University, Makassar

*Correspondence to: Rafikah Hasyim, Department of Oral Biology, Faculty of Dentistry, Hasanuddin University, Makassar

rafikahhasyim@gmail.com

Received: 30 September 2019

Revised: 5 January 2020

Accepted: 28 March 2020

Available Online: 1 April 2020
Keywords: First permanent molar, Suburban area, 5-6 years old

Cite this Article: Marhamah, Hasyim R, Wulansari DP, Yunus M, Handayani H, Sumintarti, Ramadhany S. 2020. Analysis of first permanent molar condition on Kindergarten student aged 5-6 years old in Eastern Suburban Area of Makassar City. Journal of Dentomaxillofacial Science 5(1): 42-44. DOI: 10.15562/jdmfs.v5i1.1011

\section{Introduction}

First permanent molar is the earliest tooth of secondary dentition. First permanent molar erupt when decidous teeth still exist in the children mouth, thereby included in mixed dentition period. First permanent molar is considered important due to its vital role in stomatognathic system, masticatory efficiency, serve as a guide for the eruption of the remaining molar teeth, and the key in Angle occlusion. ${ }^{1}$ The first permanent molar is the most important oral masticatory unit playing a fundamental role in favorable occlusion evolution, and due to its wide occlusal surface, it is more effective in chewing food than any other teeth. Because first permanent molar is erupted during mixed dentition period, parents are often unaware of the presence of this teeth, thus they have high risk of exposed to caries risk factor thereby often result in teeth destruction or premature loss of first permanent molar. ${ }^{2}$

Decay of first permanent molar constitutes the biggest component of decayed missing filled tooth index (DMFT) among children and adolescents. Severe caries on first permanent molar often cause pain and infection thus diminished dietary intake and malocclusion. ${ }^{3}$ Dental caries is one of the most researched oral diseases and results from a chronic process that occurs after a certain amount of exposure to a cariogenic diet and to tooth-susceptible microorganisms. Caries is considered a multifactorial condition that is transmitted locally and is one of the most prevalent pathologies in childhood. ${ }^{4}$

Dental caries is a multifactorial disease that requires a host, nutrient and bacteria which produce acid. The bacterial plaque in the mouth feeds from substrates and produces acid causing tooth decay.

An inappropriate diet of the child and unbalanced consumption of chocolate and sweets, in addition the inability to observe the oral health properly, cause tooth decay. Since children are not aware of the importance of oral hygiene and are not able to brush their teeth properly, it is their parent's responsibility to take care of their children oral and dental health. ${ }^{5}$

Kindergarten students aged 5-6 years old have at least one erupted first permanent molar should received a better attenttion from their parents in terms of dental and oral health care, because these kids are susceptible to first permanent molar caries due to their habits in chocolate and sweets consumption as well as inproper tooth brushing method.

A study from China demonstrated that $75 \%$ of children consumed snacks in between meals showed a statistically significant correlation between snacks and high caries prevalence (35\%). In Spain, children who brushed their teeth only once a day had a higher frequency (55\%) of caries compared with children who brushed twice a day $(20 \%){ }^{6}$ 
Considering the variation in the available information, this study aims to analyze the first permanent molar condition on kindergarten student aged 5-6 years old in eastern suburban area of Makassar city along with the associated factors.

\section{Material and Methods}

This study was a descriptive observational study on 100 kindergarten students from four schools in Tamalanrea District, Makassar City. Data was collected with clinical examination. Data was gathered in terms of DMFT status of first permanent molar and OHI-S. Data was analyzed with descriptive statistics and t-test. In this descriptive cross-sectional study, 100 5-6-year-old students were selected randomly. Data was gathered with clinical examination and a questionnaire, collecting data of DMFT of first permanent molars, OHI-S, oral hygiene and nutrition habits. Statistical analysis was performed by descriptive statistics and t-test.

All study samples have at least one first permanent molar erupted. Kindergarten students whom first permanent molar not erupted yet, were excluded from this study. Study samples were examined clinically with a dental mirror and an explorer under artificial light. The students were given oral hygiene instructions and introduced to a clinic to receive dental treatments, if necessary. The evaluated variables included gender, DMFT, OHI-S, frequency of tooth brushing, and nutrition habits.

The simplified oral hygiene index (OHI-S) is a common index, in which six dental surfaces are scored, four from posterior and two from anterior teeth. The scoring can be done fairly rapidly and consistently. OHI-S scores $0-1.2$ were considered to indicated good, 1.3-3.0 moderate, and 3.1-6.0 poor oral health status. While the DMFT index is one of the simplest and most commonly used indices in epidemiologic surveys of dental caries. It quantifies dental health status based on the number of decay, missing and filled teeth.

Questionnaire was filled by the examiner by interviewing the study sample in regards of nutrition habits. Data were analyzed with descriptive statistics and t-test using computer software. In this study, $\mathrm{P}$ value $<0.05$ was considered statistically significant.

\section{Results}

A total of 100 kindergarten students aged 5-6 years old were included in this study, but only 60 students were included due to the emergence of their first permanent molar. DMFT score for first permanent molar are presented in table 1.

Table 1 showed there were no missing first permanent molar in study sample, but the decay score were slightly higher in boy compared to the girl.

Table 2 showed number of decayed, missing, and filled teeth of DMFT score in relationship to tooth number in 5-6 years old kindergarten students. Table 2 showed that lower teeth have higher number of decayed as well as filled teeth.

Table 3 showed that out of 70 samples, there were 38 have moderate oral health status, 22 have good oral health status, and 10 have poor oral health status, while oral health status in girls (mean OHI-S score, $1.051 \pm 0.871)$ was better than boys (mean OHI-S score, $1.475 \pm 1.085$ ).

Table 1 DMFT score for first permanent molars on 5-6 years old kindergarten students

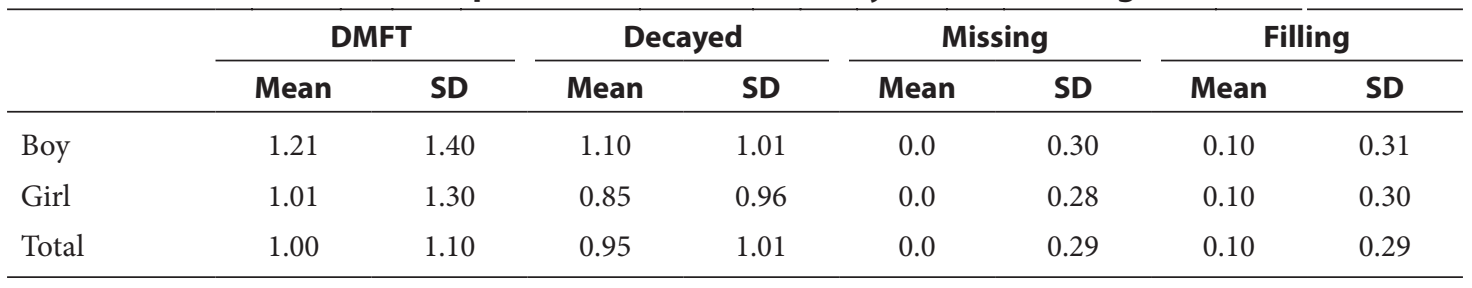

Table 2 Number (\%) of decayed, missing, and filled of DMFT score according to tooth number in 5-6 years old kindergarten students

\begin{tabular}{|c|c|c|c|c|c|c|c|}
\hline & Right upper & Left upper & & Left lower & Right lower & & \\
\hline Teeth & molar (16) & molar (26) & p value ${ }^{*}$ & molar (36) & molar (46) & $\mathrm{p}$ value ${ }^{*}$ & p value $e^{* *}$ \\
\hline decayed & $8(11.4)$ & $8(11.4)$ & $\mathrm{p}=0.100$ & $10(14.29)$ & $14(20)$ & $\mathrm{p}=0.08$ & 0.045 \\
\hline filled & $2(2.86)$ & $2(2.86)$ & $\mathrm{p}=0.100$ & $4(5.71)$ & $3(4.29)$ & $\mathrm{p}=0.100$ & 0.051 \\
\hline missing & $0(0)$ & $0(0)$ & & $0(0)$ & $0(0)$ & & \\
\hline
\end{tabular}

* comparison of left and right sides; t-test

** comparison of four first permanent molar; t-test 
Table 3 Mean DMFT of first permanent molar in relationship with OHI-S

\begin{tabular}{lccc}
\hline OHI-S & Total & Mean DMFT & SD \\
\hline Good & $22(31.43 \%)$ & 1.01 & 1.00 \\
Moderate & $38(54.29 \%)$ & 1.98 & 1.50 \\
Poor & $10(14.29 \%)$ & 3.10 & 1.65 \\
Total & 70 & 1.65 & 1.25 \\
\hline
\end{tabular}

OHI-S score 0-1.2 indicating good, 1.3-3.0 moderate, 3.1-6.0 poor oral health status

\section{Discussion}

This present study, mean DMFT of boys $(1.21+1.40)$ were higher compared to the girls $(1.01+1.30)$. The result of this study was in line with the study by Hiremath ${ }^{7}$ where the mean $\mathrm{dmft}$ in girls were 2.88 and boys were 3.15. In explaining the consistent trend of caries rates being higher in females than males, all contributing factors must be considered, such as genetic contribution, saliva, substrate/diet, psychosocial and economic factors, time, as well as systemic correlation. ${ }^{8,9}$

The present study showed that none of the participants had their first permanent molar that were restored with fissure sealants, indicate the underutilization of fissure sealants. And the increased awareness of oral hygiene among individuals over time as well as differences in diet and oral hygiene habits may be reasons for the lower amount of tooth loss in the evaluated samples of this study.

Out of 70 samples, there were 38 have moderate oral health status, 22 have good oral health status, and 10 have poor oral health status, while oral health status in girls (mean OHI-S score, $1.051 \pm$ 0.871 ) was better than boys (mean OHI-S score, $1.475 \pm 1.085)$.

The observed oral hygiene status among the 5-6year-olds necessitates implementing preventive as well as restorative measures to improve the oral health status of the young population. The underlying problem should be addressed by emphasizing on prevention of dental caries, which could save lot of resources from a public health perspective. Community based preventive oral health programs on practices of adequate oral hygiene should be implemented. School program should be promoted through integration into the school curriculum and oral health care preventive services to target the growing problem of dental caries among school children. ${ }^{10}$

Oral health education should be raised in the community through oral health campaigns and adequate access to public preventive and restorative dental programs and services should be ensured for all the children. ${ }^{11}$

\section{Conclusion}

The observed oral hygiene status among the 5-6 years old necessitates implementing preventive as well as restorative measures to improve the oral health status of the young population. Delivering oral health instructions as well as emphasizing on the importance of oral health to the children and their parents is recommended in order to promote the oral and dental health of the population.

\section{Acknowledgment}

Thank you to Faculty of Dentistry at Hasanuddin University for support with this research.

\section{Conflict of Interest}

The authors report no conflict of interest.

\section{References}

1. Pontigo-Loyola AP, Márquez-Corona ML, MinayaSánchez M, et al. Correlation between the caries status of the first permanent molars and the overall DMFT Index: a cross-sectional study. Med (Baltimore) 2020;99: e19061.

2. Espinoza-Espinoza G, Corsini G, Rojas R, et al. The cost-utility of school-based first permanent molar sealants programs: a Markov model. BMC Oral Health 2019;19: 293.

3. Borges, Silvana T, Schwanke, et al. Factors associated with caries: a survey of students from southern Brazil. Rev Paul Pediatr 2016;34: 489-494.

4. Jetpurwala M. Parental perception of the importance of the permanent first molar in their children. J Dentist Child 2020;87: 26-30.

5. Heydari, Alireza. Parental knowledge and awareness of the first permanent molar. Int J Clin Pediatric Dentist 2018;11: 382.

6. Maciulskiene, Vita. Estimation of caries treatment needs in first permanent molars of Lithuanian 5-6-year-old children, based on caries lesion activity assessment. Medicina 2020;56: 105.

7. Hiremath A, Murugaboopathy V, Ankola AV, et al. Prevalence of dental caries among Primary School Children of India: a cross-sectional study. J Clin Diagn Res 2016;10: ZC47-ZC50.

8. Ferraro M, Vieira AR. Explaining gender differences in caries: a multifactorial approach to a multifactorial disease. Int J Dent 2010;2010: 649643.

9. Soumya SG, Shashibhushan KK, Pradeep MC, et al. Evaluation of oral health status among 5-15-Year-old School Children in Shimoga City, Karnataka, India: a cross-sectional study. J Clin Diagn Res 2017;11: ZC42-ZC47.

10. Nazir MA, Al-Ansari A, Al-Khalifa KS, et al. First permanent molar caries and its association with carious lesions in other permanent teeth. J Clin Diagnostic Res 2019;13: ZC36-ZC39.

11. Bamgbose BO, Abdu ZS, Enahoro O. A rare clinical finding of mandibular distomolar at Aminu Kano Teaching Hospital. J Dentomaxillofac Sci 2019;4: 117-119.

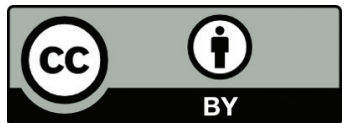

This work is licensed under a Creative Commons Attribution 